T $\mathbf{H} \mathbf{E}$

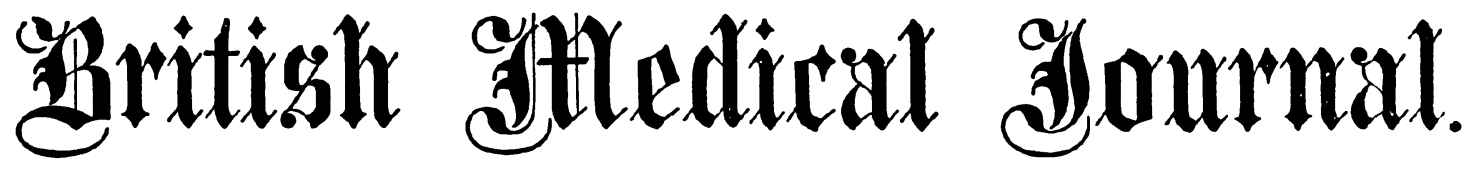

THE JOURNAI, OF TIF BRITISH MEDICAL ASSOCIATION.

LONDON : SATURDAY, JUI,Y 2, 1904.

\section{An Aùtrezs}

\section{THE HOSPITAL IDEAL AND ON THE CONCEN- TRATION OF EARLY MEDICAL STUDIES IN LONDON.}

Delivered to the Students of St. Thomas's Hospital .Medical School on the occasion of the Distribution of Prizes on June 24th, 1904.

By Sir ThOMas BARLOW, Bart., K.C.V.O., M.D., Physician, University College Ilospital : Member of the Senate of the University of London.

I.-The Hospital Ideal in Private Prictice. Mx first duty is to congratulate those who have won and received this day the highest distinctions which your school can confer. You have a right to be proud of your sucress, and your teachers and fellow-students rejoice in it; but I can well believe that you will prize most of all the congratulations of the home circle, which are, indeed, fitly represented by the gracious presence of our lady visitors on this occasion. Let cynics inveigh as they will against the stale, the trite. and the commonplace, but the prize-giving day must always be a redletter day to every succeeding generation of students, so long as they are made of good human stuff and still retain a store of generous enthusiasm. Now let me claim the privilege of years to say a few words to you arising out of the associations of the day. First of all, I trust that you will not put aside the examinations and the struggles which have led to your success. There must have been a certain amount of scientific knowledge which you have been compelled to formulate, to summarize, and more or less to critici\%e in preparing for these examinations. Be determined that some portions of that material shall be made the basis for further elaboration in your own way in the years to come. It is the charm of our occupation that we can all add something to the sum of useful and fruitful discovery. It may be a very humble contribution and may never see the light of publication, but it may be helpful to us in the study of the natural history of some common disease and in the practical relief of some human suffering. What I wish to drive home to you on the threshold of your active lives is that to have some line of inquiry always ready for fresh reading, observation and experiment is the way not only to get special knowledye on that line of inquiry but to educate your receptivity for fruitful knowledge in general.

I must say a few words to those who have striven in the competition but have failed to gain the prizes which have been distributed to-day. I beg you not to be discouraged and on no account to shirk future examinations because you have failed in these. Many a man who has come off second best in anatomy or physiology has carried everything before him in medicine or surgery. Moreover, the first-prizemen in college are not always those who carry off the first prizes in active life. But whether you gain prizes here or elsewhere, I am sure that for the successful learning of your profession you must never shirk examinations, especially viva voce ones. In some of the early subjects of our cirrriculum there is an immense mass of what $I$ may call brute facts, and one of the best ways of remembering them is to link them together by as many associations as possible. Wo not even undervalue the painful association which arises from being gibbeted before your fellow students by a teacher who is merciless to inaccuracy and relentless to slipshod statement, whether of fact or inference. The desideratum is that you should make the most painstaking reviews of your failures and never forget them, and this is really the precursor of what you will find you have to do throughout your whole professional life. Unce again, with regard to examinations, a venerated teacher of mine used to say that we have never finished with them, but that we are doomed to undergo them right through our livesexaminations by patients and by patients' friends taking the place of the ordeals which you have just survived. Remember that the capacity for terse and forcible speech and for lucid explanation are amongst the gifts which pre-eminently tend towards efficiency of life. Cobden used to say that the real test of oratory was whether it succeeded in persuading or not. If you wish to succeed in persuasion you must understand your auditor's point of view and thr question which he has asked, or is ready to ask, and you must also understand exactly what you wish to say. Fothing helps to cultivate this faculty more than facing written and viva voce examinations. One of the greatest hindrances to a young doctor is self-consciousness. It is the foundation of mucl. shyness, conceit, and brusquerie. One of the collateral advantages of viva voce examinations is that they help you to get rid of self-consciousness and compel you to think of the subject in hand rather than of yourself.

Gentlemen, some of you are here for the last time as students, and you are soon to enter on responsible professional life. I have already found myself trenching upon this, but I should like to sny a fer words to you about your future ideals of life and conduct in their relation to your student course. I assume that most of you have acquired your general education at a public school, and possibly at one of the universities, and. after working at your preliminary scientific and early medical studies, that you have gained your knowledge of practical medicine and suruery within the walls of the hospital and at the latter part of your course. It is very unlikely that any of you have entered upon the study of medicine by the old-fashioned apprenticeship system. There is much to be said about the merits of the old and the modern methods, but I will not discuss them. There are never wanting amongst our learned, grave, and reverend seniors those who are ready to play the part of laudator temporis acti. Many a young fellow just starting in practice has been discouraged by being told that he is quite ignorant of the art of managing patients, however learned he may be in modern methods of investigation. $\mathrm{He}$ is told that private patients are so very different from hospital patients, that elaborate examination is quite out of place, and that the first of all requirements is to relieve symptoms, and to be ready with prescriptions, and that the question of diagnosis is quite subsidiary. The patient must be pleased with the doctor and the friends must also be pleased. A careful study of likes and prejudices should be made, and these should be taken account of at every turn. The young doctor must never acknowledge that he has any doubts, he should never hesitate, or admit that he has made a mistake. and he should lose no opportunity of accentuating his own insight and foresight, especially if he can at the same time belittle some one or other of his professional brethren. To all this cynical advice of the Lord Chesterfield type I venture to 
say that for you, trained in the hospital, there is a more excellent way. Worldly wisdom and savoir faire are not wholly to be despised. We cannot afford to dispense with them. but they are not the qualities which you should covet at the outset of your career. Leave them, I pray you, for the period of disillusionment which comes knowledge which you have learned in the laboratory and the wards and the enjoyment which has come to you in taking a humble part in the successful results of surgical skill or in following the guidance of rational medicine. It is your métier primarily to learn and to know as the basis of intelligent action, rather than to please. Remember the lesson of the hospital, that diagnosis is nine-tenths of our work. For although it is true that the right lines of treatment are sometimes difficult, and now and then there is scope for divergence of opinion, yet in the vast majority of cases it is not so. The real crux is to find out what is wrong; then the treatment is pretty obvious. The variations of opinion as to treatment mostly depend on incompleteness of diagnosis. When from the nature of the case the diagnosis must be incomplete, a wise man will avoid heroic remedies and keep to simple therapentirs. House-physicians can be classified under many different categories, but the two fundamental types are the one who writes out a good present state of his patient and then waits awhile, and the other who fills the medicine sheet with elaborate prescriptions directly the patient is admitted and before it is possible to arrive at any judicial estimate of his condition. There is no doubt which of the two makes the best practitioner. But, with respect to treatment, it cannot be denied that you will have greater personal responsibility in private practice than you have had even as a resident in hospital. Much of the regulation of diet and of personal hygiene goes by rule in the hospital, and we have no necessity to intervene, as it is carried out by our good friends the sisters and nurses. We are apt to forget that much of this needs special direction on our part in private practice. Moreover, the hospital pharmacopoeia and the convenient abbreviations of the contents of ordinary mixtures are partly responsible for our ignorance about the dosage of many drugs. Never forget, in your ardour for investigation, that the smallest details for the relief of pain are worthy of thought and sturly, and that clothing, food, and exercise admit of scientific regulation as well as the quantity and combinations in medicines. Besides the actual body of facts and instruction in the modes of investigation which you learn from your teachers in hospital, there are some collateral methods of learning which, if you avail yourselves of them to the full, will prove of enormous value in your practice. O these I should like first to refer to the systematic study and record of blunders. I have already referred to this in regard to examinations on the early subjects in which memory for brute facts plays so large a part. Jut I make no apology for referring to it again in regard to clinical work. Clinical blunders and the blunders of private practice are of two kinds -the inevitable and the avoidable. The inevitable blunders depend on the limitations of our knowledge, and these ought to get less if we lreep abreast with the advancing tide of science. Of the avoidable blunders some depend on deficient skill, whether it be in investigation or in handicraft. These can be largely overcome by practice and by reflection. But the chief avoidable blunders arise from sheer carelessness and idleness, taking things for granted instead of going steadily through the present state, and reviewing and revising everything from day to day. We are often blamed unjustly for results which are beyond our ken and beyond our power to modify or prevent. On the other hand, we often receive credit for what we have not deserved. The vis medicatrix Nature is a kind friend to the doctor, condoning his faults, never jealous of reputation, but quite willing that he shall have all the praise for beneficent results. But rest assured, in the long run, careful and painstaking investigation will reap some reward, even when the results are not successful, for it is the safest and most legitimate foundation on which you will build up the confidence of your patients. One of the most striking differences between the life of the hospital and that of the young practitioner is in the comparative loneliness which he experiences in everything which concerns the process of investigation. Think of the all-embracing atmosphere of discussion, of friendly criticism, of verification and disproof, which is to be found within the clinical wards. Recall the mutual friendly gibes of physicians and surgeons with respect to the merits of expectancy or of early or late interference, and the genial and impartial anecdotes of the registrars concerning the divers errors of diagnosis, and the home thrusts of housephysicians and house-surgeons who will criticize the lines of practice of their respective chiefs but loyally deny to anybody else the privilege of criticizing them, and the keen and trenchant estimates made by the whole body of the students. More than all, remember the sure and gradual survival of the fittest as to the value of multifarious methods of treatment which emerges after a longer or shorter time. Think, again, of the valuable side-lights thrown upon cases by the new chemical, physical, and bacteriological methods, of the information imparted to physicians by cranial, thoracic, and abdominal surgery, of the help derived from the ophthalmoscope and other instruments of precision. Finally, remember the great arbiter and revealer of our work, the post-mortem room, where dogmatism and arrogance and carelessness and slovenliness receive their appropriate rebuke and enlightenment. In the hospital you are literally living amongst a crowd of witnesses who reckon up your work and continually bring it to the touchstone of truth and utility. Contrast with this the loneliness of early private practice. You have few chances of comparing notes with others who are better informed than yourself, many of your cases are trivial, and of those that are obscure or fatal you have but scanty opportunities of post-mortem verification. But remember that you will be subjected to criticism which, though unenlightened, may nevertheless be wholesome. If you have utilized your opportunities at the hospital you will recall that when you have done your best in the steady plodding of systematic casetaking, and are still in the dark, occasionally i!lumination comes from a casual remark of the patient or from some onlooker who approaches the case de novo. The man of wits is persevering in his own investigations, but he is ready to take a hint from the humblest of his fellow workers. So in private practice you will find, if you cultivate the frame of mind which listens to and weighs the observations of others, you will not only gain many a hint by the way, but you will disarm captious faultfinders and secure the adhesion of some who might be unfriendly.

Although there is nothing to compare with the advantage of hospital life in respect to the acquisition of knowledge from one's fellow workers, I urge you to utilize every chance, especially in the earlier period of your practice, of keeping up scientific intercourse with your brother practitioners. You will find that the generous give-and-take of friendly discussion is the best of all preventives of professional jealousy. I trust that you have learnt the difficult art of taking notes that are at once exhaustive and terse. All hospital notes tend sadly towards prolixity. I would like to sec every clinical clerk when he has finished the ward reports make a concise abstract for his own use of his cases and carefully index them all, mentioning the salient lessons as to physical signs and post-mortem verification, and enumerating the features in which they bear out the textbook type and those wherein they diverge from it. In private practice although you may not be able to keep extensive and detailed notes, if you have learnt the art of making concise abstracts, there is no reason whatever why you should not formulate valuable and extensive experience with vory little expenditure of time. In the pursuit of your profession on these good old hospital lines you will gradually gain the confldence of your patients, and, as I have said, this confidence will be based on sound and solid foundations. In these days of faith healing, of Christian science falsely so-called, of hypnotism, of charlatanism of every kind, inside the profession as well as outside, there are some pitialls into which the young practitioner may tumble. One of these is the exaltation of his own personality and undue influence over those whom he has to treat. In every calling of life, genuine sympathy and the determination to understand the outlook of others are enormous aids to success, and deservedly so; and there is no occupation in which a broad and enlightened charity is so appropriate as it is in ours. Nevertheless, I would remind you that in hospital practice there is a certain brevity, a businesslike straightforwardness, and a simplicity in dealing with people which are very wholesome, and which appear to be justified in their general result. I think the nearer we approach to that in private practice the better for us all. Let us not forget that, although subject to criticism, there is a considerable area in which we are independent, and we shall do well to guard that independence jealonsly. Let us not get too far away in our professional intercourse with people from the 
plain, straightforward duty offinding out what is physically wrong and trying to set it right. That is our primary function and, if we keep it primary, the other parts of conduct may be trusted to find their proper places in the pattern of our lives. The perfect openness and outspokenness of the hospital rule is one of its perennial charms. No secret remedies, very few confidences, everything aboveboard, all out in the open. It makes one think of old Bishop Ken's lines-

\section{Let all thy converse be sincerc.}

$$
\text { Thy conscience as the noonday clear. }
$$

of course the conditions in private practice are different and it is impossible to act as though they were identical. What I am claiming is, that for you, trained and nurtured in this free and invigorating atmosphere, the ideal of conduct which should be to you the touchstone of your professional life is the hospital ideal. And you will be the first to deny the shallow and unjust accusation made by sentimentalists that the hospital tone is hard and unsympathetic. It is neither hard nor unsympathetic, and, let me add, it is neither mawkish nor maudlin.

I will conclude this part of my subject with an extract from one of the letters of the great Puritan physician, Thomas Sydenham :

"I continue, and will continue, to learn and to promote to the best of my powers the methods for the treatment of diseases, and to instruct others (if such they be) who have less skill in practice than myself. Meanwhile my fame is in the hands of others. I have weighed in a nice and scrupulous balance whether it be better to serve men or to be praised by them, and I prefer the former. It does more to tranquillize the mind, whereas fame and the breath of popular applause is but a bubble, a feather, and a dream. Such wealth as such fame gives those who have scraped it together and those who value it highly are fully free to enjoy, only let them remember that the mechanical arts (and sometimes the meanest of them) bring greater gains and make richer heirs."

II.-A Plea for Concentration of the Teaching of the EARL M Medical STudies in London.

And now having finished these fragmentary admonitions, let me say a very few words on another subject which I think is of importance to you who are students of one of the most distinguished constituent institutions of what $I$ venture to call the great London School of Medicine.

You are rightly proud of this your Alma Mater and of the place it has long held in the theory and practice of our art. But it is right for all of you to think also of the larger interests of the study of medicine in this metropolis. The real reason, I venture to think, why your teachers and my friends have honoured me by asking me to address you to-day is a growing conviction that it is imperative that there should be more solidarity between the medical schools of London, and that we ought to close our ranks and ask what we can do to further the study of medicine as a whole.

We are accustomed to say that London is the greatest clinical centre in the world, and so it is; but how badly organized and inadequately used for the purposes of instruction and for the solid advance of medical knowledge! With such an embarras de richesses how few of our students reap a tithe of the stores of the clinical wealth which is around them. I quite agree that the student's time is fully occupied up to the period of his qualifying examination. But between the period of taking the qualifying examination and that of the final medical or surgical degrees there is an interval which is partly occupied by resident hospital posts, but not entirely so. In this interval much might be accomplished by young and ardent workers in the elucidation of clinical and pathological problems under the guidance of their seniors and of special instructors in modern scientific methods. Let me remind you that St. Thomas's was one of the pioneers of hospital clinical laboratories, and that the first director of your laboratory, a distinguished student of this school, Dr. Louis Jenner, has lately been snatched away from us in the plenitude of his powers. He was a true martyr to science in that he lost his life in the performance of self-denying researches on important problems of medicine. He was so modest and retiring that his work was known to few beyond the circle of his teachers and colleagues, but they recognized his rare conscientiousness and fidelity to accurate investigation and the great loss which experimental pathology has sustained from his untimely death.

The clinical laboratory is a step in the right direction, but it is only a short step. If you wish to give the advanced student more opportunities for utilizing clinical and path- ological material his advanced teachers must have greater opportunity for devoting time and labour to instruction and personal research alongside of their practical ward work.

(ientlemen, my address to you to-day has been a recurring panegyric of the hospital, its methods, its spirit, and its ideals, and I wish now to enforce upon you that the advance of scientific medicine will, I believe, be most effectively secured by the union and development side by side (1) of remedial practical work for the poor in the wards; (2) of the every-day instruction of the undergraduate students; and (3) of research of teachers and post-graduate workers under the self-same roof, or in close and active relations with the hospital. Valuable as separate pathological institutes may be, there is a virility, a renewal of youth, and a far-reaching reciprocal advantage in this three-fold union which the perfect huspital ought to supply like a great and beneficent republic of medicine.

And how can this ideal be made practical:- Surely it will have to be recogni\%ed that clinical work, both in regard to advanced teaching and research, needs a much more complete organization than it has received hitherto in Iondon. It is constantly stated that money is always forthcoming for the benevolent gide of hospitals, but seldom for the endow ment of advanced teaching and research ; but I tirmly believe if we ourselves rose to the occasion and were prepared with practical schemes the money would be forthconing. Meantime, what can we ourselves do in the way of initial steps to hasten on this development? Let us accept the lessons of the time and see what can be accomplished in the way of combination. What a prodigal waste of time and effort we behold when we survey the practical working of our medical schools: We sec so many men teaching early subjects of the curriculum which have no longer any relation to their active life work. and thus they are taken away from scientific inquiry of practical bearing to do what to them is drudgery, and which, morever, could be better taught by specialists.

Then there is the humiliating situation that when a man devotes himself to teaching one of these early subjects of the medical curriculum, relinquishing private practice, and andeavouring by research to advance the sum total of knowledge in that department, he is brought to a dead stop by the limited number of his class and the small remuneration which the absence of endowment involves. There is, moreover, the urgent necessity of providing and paying for efficient demonstrators in the practical departments, and again the expense in maintaining the apparatus and reagents necessary for adequate tearhing. The constant advance of knowledge makes constantly increasing demands in these departments. Now let us realize that modern universities have grown up, especially in some of the great provincial cities, and that these can appeal to wealthy and liberal citizens in whom the municipal amour propre is blended with enlightened generosity. Is it strange that every medical school in London has lost one or more of its gifted special teachers: They have been tempted not only by emoluments, which are net one whit too great for the valuable work which they secure, but also by the generously equipped laboratories which afford abundant opportunity for original research without let or hindrance. How, then, should the concentration be brought about? Surely by combining together in certain centres the teaching of those early subjects which are quite independent of the hospital association. If this plan were adopted larger classes would be formed, and they could be more profitably worked than under present conditions.

It would then be possible to secure for the special subjects professors adequately remunerated, able and willing to give time to both teaching and research, and large laboratories and dissecting rooms properly equipped would require to be built. For a vast city like London, at jeast three such centres should be instituted. We trust that one of these may shortly be established at South Kensington; the nucleus of another will soon be available by reason of the forthcoming incorporation of University College with the University of London. Through the munificence of Sir Donald Currie this will be rendered possible by the complete severance from University College of the department for the later medical studies and its installation close to the hospital. It seems clear that a third such centre would be absolutely nectesary on the south side of the Thames, and in such a centre St. Thomas's Hospital Medical School would naturally be greatly concerned.

What should be done with those portions of the school buildings which would become unvccupied in consequence of the removal of the chemical, biological, anatomical, and 
Physiological departments from any given school? A more generous equipment could be given for the teaching of medicine, surgery, and obstetrics, and space could be found for further development in the direction of pathology, pathclogical chemistry, bacteriology, and other allied branches. Then we might count not only on giving greater opportunities for practical instruction to undergraduown post-graduate research by our versities. What would become of the teachers at present concerned in the early studies, and who would be dispossessed by the above arrangement? The answer to this question is that, besides the professors, a considerable number of demonstrators will be required in the new centres, and that those who on patriotic grounds for the good of their school have given both time and labour to this work will be emancipated from druagery, and will find opportunity for research and for giving instruction to advanced students in subjects which are cognate to their own life-work.

But will the severance of these early studies and their installation in central institutes weaken the attachment of students to their hospital school? Surely not. When young men come to London for their medical curricula they will enter at one or other of the centres as may be most convenient, and, having acquired the necessary knowledge of the prelininary and early subjects, they will then choose the hospital school which on the whole appears to them the most desirable. They will be in identically the same position as men coming from the old universities who have pursued their early studies in the medical department of either Oxford or Cambridge. Will anybody maintain that these old university graduates are less devoted to their hospital school in London than any other London students ?

Depend upon it, anything which leads to economy of labour, to greater efficiency, to unification and consolidation of interests will very soon justify itself. The removal of anxiety as to the equipment of the preliminary and early studies in any given school will allow the teaching staff to concentrate its energy on the later study, and the existence in this town of three great centres for education in preliminary and early subjects, efficiently and generously equipped with professora, with demonstrators, and with laboratories, will go a long way towards establishing the foundations for supremacy of the medical ellucation in London. When these foundations are laid, sure and strong, we may hope to cope successfully with the development of advanced studies and advanced research in every school hospital in this metropolis, and we may then look forward to London becoming in fact as well as potentially the greatest clinical school in the world. It would be most undesirable that these centres should be identical. Differences in method and equipment tend towards the survival of the fittest, and an honest rivalry can bring nothing but good to the medical body politic.

Finally, to sum up the arguments which I have submitted to you, what can be more fitting than that these centres should be established as constituent parts of the teaching University of London? In this way the best guarantees will be taken for permanence of equipment and management, and for breadthand liberality of view in future development.

Moreover, the intimate association of the great body of medical students of London in such a way would contribute the largest and most important contingent in building up the teaching side of the University, and the hospital medical schools would maintain their vital independence, and, freed from embarrassing and unbusinesslike obligations, would be able to make real advances in scientific medicine and in its teaching.

Gentlemen, whilst rejoicing with you in your individual successes this day, and exhorting you to cherish the good name and the fame of your hospital and school, I submit for your patriotic consideration the claim which I have imperfectly stated for the educational needs of medicine in London as a whole.

A French Colee of Medical Etirics.-At the Congress of Professional Medicine held in Paris in 1900, it was decided that a committee should be formed for the purpose of drawing up a code of medical ethics. It was intended that this code should be handed to every one taking a medical degree on the day of the presentation of his inaugural thesis. The Committee has just published the result of its labours in the form of a pamphlet bearing the title Avant-projet d'un Code de Déntologie Medicale. The pamphlet consists of two parts, an introduction dealing with the principles of medical ethics and a code of 112 clauses.

\section{A Cliniral Perture}

\section{A('UTE MAIIGNANT ENDOCARDITIS. Delivered May 6th, 190\%.}

By Sir DYCE DUCKWORTH, M.D., LL.D., F.R.C.P., Physician and Lecturer on Clinical Medicine, St. Bartholomew's Hospital.

Grentlemen, - I propose to discuss to-day the case of a boy who was brought into Matthew Ward on April 2oth, and who died after a fortnight's illness with some remarkable symptoms. H. E. M., aged 13. a schoolboy, was in his usual health on April 12th. His mother a respectable and intelligent woman, gave us the following history: The boy attended echool on that day, but had a fall from a lamp-post on his head, which appears to have stunned him. He was one of nine healthy children, and had had no important illnesses - certainly no rheumatic fever. He came home, feeling faint and poorly, and was put to bed, where he remained under medical care till April 2oth, when he was admitted to the hospital. On the i8th he complained of pains in his limbs and general tenderness. There was constipation, but no vomiting. His temperature had varied from $101^{\circ}$ to $103^{\circ}$ before his admission. He was semi-comatose when brought in on April 2oth. The family history was unimportant. The boy lay still in bed, but was tender all over when touched. His complexion was dusky red. He was fairly well nourished. There were numerous petechiae on the trunk and limbs, which appeared to be due to flea-bites. The temperature was $100.2^{\circ}$; the pulse 100, of moderate volume and low tension. Respirations 28 , shallow. The conjunctivae were much injected, the pupils large and equal, reacting to light. No discharge or ill odour at either ear, and no swelling in the mastoid regions. The lips were dry; tongue dry and glazed, not furred. No injury to the scalp or skull could be detected. A few small glands were palpable in the neck. There were signs of bronchitis in the lungs, which did not expand very fully. The heart's apex beat was in the fifth left space, just outside the nipple. The dullness extended only to the left sternal line. Dr. Gould found, on admission, a slight murmur with the first sound at the apex; second sound natural. (This murmur was not recognized by me some two hours subsequently, and never on any succeeding day, although Dr. Gould heard it again on another occasion. The abdomen was full, and moved little on respiration. No resistance or special tenderness over it. The spleen was palpable, the liver natural. The limbs were spare. No signs of arthritis or epiphysitis. The knee-jerks were natural. An ecchymosis was noted over the left internal malleolus. The urine was of sp. gr. 1010, and contained a trace of albumen.

The first impression was that the boy was probably suffering from enteric tever. On testing the blood for a GrünbaumWidal reaction, this was found negative. The boy became almost comatose, and had to be fed by the nares with milk, beef-tea, and brandy, and the nitro-hydrochloric acid draught of the hospital was given. Fresh petechial rash appeared daily on the trunk and limbs, and the case now assumed many features of spotted typhus fever, save in respect of the large pupils. Ile passed urine under him constantly. On April 23rd the pupils were unequal, the right the larger. Some rigidity of the right leg was noticed, also some retraction of the head and slight arching of the trunk. There was thus evidence of some cerebro-spinal meningitis. The right optic disc was fairly natural, only some undue fullness of the veins being apparent. A little blood-stained discharge came from the right ear, but it came from outside the middle ear. Dr. Gee and Dr. Ferrier saw the boy with me on this date, and it was decided to examine the blood and the cerebro-spinal fluid for evidence of some special variety of toxaemia. Ten c.cm. of blood were removed from a vein in the right arm, and as much fluid from a lumbar puncture, hoth being kindly examined by culture by Dr. Horder. The boy gradually lost strength, his temperature ranging from $102^{\circ}$ to $104.6^{\circ}$, became more comatose, had some blood-stained discharge from the nose, and died on April 25th, the fourteenth day from his first symptoms of illness.

It was clear that this case was one of acute toxaemia, though it was not easy to discover the exact nature of it. The condition of the blood showed a good proportion of xanthocptes$4,544,000$-and some degree of leucocytosis-14,000-during life. The results of the cultures were only made known on 